\title{
nature
}

\section{Dutch researchers' freedoms and responsibilities}

Following damaging cuts in public spending last year, a new research policy in the Netherlands promises more freedom to researchers to set priorities. But national interests should not be forgotten.

$\mathrm{B}$ y comparison with his predecessor, the Dutch science minister Loek Hermans is an unassuming character. He doesn't want his ministry to tell universities what research to pursue. In marked contrast, the previous science minister, Jo Ritzen, wanted to prescribe a university's number of PhD students. Although Hermans' job is to take responsibility for the state of research in the Netherlands, he is happy to let researchers have much more say in setting priorities. Ritzen, on the other hand, wanted to do the prioritizing.

For all Ritzen's determination to link research to socio-economic goals, in the end he seems to have stumbled on several counts. He failed to carry through a transfer of funds from the universities to the research funding agency, the Netherlands Organization for Scientific Research (NWO), in a bid to strengthen central prioritizing. And he failed to prevent significant cuts in Dutch research last year. All the signs are, now, that Dutch research is set for a more positive future thanks to Hermans' greater degree of political clout within the Dutch cabinet.

Last month, Hermans unveiled a plan that embodies his philosophy but which would also, if implemented, take universities a welcome step back from overly burdensome accountability. Under the terms spelt out in Science Budget 2000, ministerial micromanagement will be a thing of the past. Universities will submit strategic plans to the NWO every four years, rather than two-yearly reports of progress to the ministry. The NWO, in turn, will craft a national research plan based on universities' submissions. In order to foster awareness of potential economic and social relevance, foresight studies developed by the independent Advisory Council for Science and Technology Policy will be available for universities to take into account as they see fit.
These changes signal increased freedom for the Netherlands' 13 research universities to develop their own strategies, and increased clout to the NWO in developing national research and innovation. It also signals more flexibility in the allocation of funds to universities, hitherto - for the past 20 years — based rigidly on outdated statistics of student numbers.

The plan deserves two and a half cheers: one cheer for enhancing the role of universities in setting the priorities of their 2.4 billion guilders (US $\$ 1.2$ billion) research budget; another for decreasing the bureaucracy they have to submit to; and half a cheer for the success of Hermans in halting the funding decline - the document announces that funding cuts previously planned for the next few years will not occur. Research agencies and universities and, eventually (too eventually, perhaps), the ministry will shift some money into an innovation fund, set to grow to at least 75 million guilders, to develop fundamental research in priority areas such as bioinformatics and cognitive sciences.

It would be wrong to conclude that the Netherlands has drawn back from the idea that science should help develop the country economically and socially. Rather, the policy shift is an attempt to set a new balance of ministerial responsibility on the one hand and, on the other, to delegate authority to universities and the NWO, trusting them not only to pursue interesting questions but also to keep the national interest in mind. The Dutch research community packs a strong punch for one so small. The new balance of forces is a liberation that researchers and their institutions deserve, but their freedom will have to be tempered with the assumption of enhanced responsibility for considering long-term social and economic goals if they want to avoid a return to micromanagement.

\section{Big Science comes of age}

Talk of the demise of Big Science is premature. But its characteristics have changed significantly.

W hen Alvin Weinberg coined the phrase 'Big Science' almost 40 years ago, the "monuments" to it that he listed - "huge rockets, high-energy accelerators, high-flux reactors" were all identified with the physical sciences. To many, high-energy physics was the prototypical Big Science, and Weinberg himself - to the chagrin of many biologists - described such endeavours as "symbols of our time".

There have been times recently when the biologists have seemed keen to take over this mantle. In the early days of the Human Genome Project, for example, there was much talk of how this would put genetics into the Big Science league. Furthermore, US politicians are sending signals that their support for particle accelerators may be ending (see page 390) just at a time when the National Institutes of Health is making its first major contributions to the construction of synchrotron radiation facilities (see page 395). It is tempting to talk in terms of the swing of a pendulum, and to suggest that biology is now beginning to enjoy the role that physics and space-based research have occupied for the past 50 years.

Such a characterization is misleading. Weinberg and those who picked up his Big Science idea were thinking of large experimental facilities that became the centrepiece of one or a few major collaborative research programmes. In contrast, the new synchrotrons and other devices are multi-user, multi-experimental facilities.

Furthermore, a key characteristic of the new facilities is that their use is not dominated by any one scientific discipline. The rapidly growing use of synchrotrons by structural biologists, or even of space missions by 'exobiologists', does not represent a take-over in any sense. Rather, both moves illustrate a more significant and longlasting trend: the growing collaboration between separate scientific disciplines, and thus the emergence at new scales of a truly interdisciplinary approach to scientific problems. Big Science is not dead - it is merely coming of age. 